\title{
Evaluation of circuit lifetime in continuous renal replacement therapy using two types of polysulfone membranes
}

\author{
Yuki Nakamura", Shinya Chihara', Hiroomi Tatsumi ${ }^{2}$ and Yoshiki Masuda ${ }^{2}$
}

\begin{abstract}
Background: For continuous venovenous hemofiltration (CWH) to achieve an adequate therapeutic effect, prolonged stable administration and a long circuit lifetime are needed. The effects of hemofilters produced using various kinds of materials on circuit lifetime in CWH have been examined, but no studies have investigated the effects of the length, diameter, or surface coating of hollow fibers. The aim of the present study was to evaluate the circuit lifetime in CWH retrospectively using two types of polysulfone (PS) membranes.
\end{abstract}

Methods: The participants were patients with acute kidney injury who underwent CWH from January to July 2017 at a university hospital. The patients were divided into two groups based on the PS membrane used: an SHG group using Hemofee ${ }^{\circledast}$ SHG (Toray Medical) and an AEF group using Excelflo ${ }^{\circledR}$ AEF (Asahi Kasei Medical). The SHG hemofilter has a longer and thinner hollow fiber than the AEF hemofilter. The target $\mathrm{CWH}$ duration was $48 \mathrm{~h}$. Circuit lifetime was defined as the time until a CWH malfunction was identified. A CWH malfunction was defined as a problem in extracorporeal circulation or either a 100-mmHg increase in the inlet chamber pressure or a 50-mmHg decrease in the filtration chamber pressure from baseline. During $\mathrm{CWH}$, the transmembrane pressure (TMP) change rate from baseline (at $0.5 \mathrm{~h}$ after initiation) was monitored.

Results: The SHG and AEF groups comprised eight and nine patients and underwent 10 and 14 sessions, respectively. No significant differences were seen between groups in patient characteristics or blood or filtration flow rate during $\mathrm{CWH}$. Although circuit lifetime tended to be longer in the SHG group, no significant differences in circuit lifetime were found between the two groups. The TMP change rate at $12 \mathrm{~h}$ after $\mathrm{CWH}$ and thereafter was significantly higher in the AEF than that in the SHG group.

Conclusion: In spite of using the same material, differences in the shape of the hollow fibers and surface treatment of the membrane affected the TMP change rate during CWH in critically ill patients. To maximize circuit lifetimes, hemofilters should be chosen based on not only their materials but also their shape and membrane surface treatment.

Trial registration: The patients in this study were registered retrospectively. Registered 12 July 2018 (302-54).

Keywords: Circuit lifetime, Continuous venovenous hemofiltration, Polysulfone, Polyvinylpyrrolidone

\footnotetext{
* Correspondence: yukinakamura@sapmed.ac.jp

${ }^{1}$ Division of Clinical Engineering, Sapporo Medical University Hospital,

South-1, West-16, Chuo-ku, Sapporo, Hokkaido 060-8543, Japan

Full list of author information is available at the end of the article
}

(c) The Author(s). 2019 Open Access This article is distributed under the terms of the Creative Commons Attribution 4.0 International License (http://creativecommons.org/licenses/by/4.0/), which permits unrestricted use, distribution, and reproduction in any medium, provided you give appropriate credit to the original author(s) and the source, provide a link to the Creative Commons license, and indicate if changes were made. The Creative Commons Public Domain Dedication waiver (http://creativecommons.org/publicdomain/zero/1.0/) applies to the data made available in this article, unless otherwise stated. 


\section{Background}

Continuous venovenous hemofiltration $(\mathrm{CVVH})$ is used to treat patients with acute kidney injury (AKI) and hemodynamic instability. Since CVVH requires prolonged and stable performance, the maintenance of a long circuit lifetime is one of the most important factors for achieving an adequate therapeutic effect [1, 2]. On the other hand, critically ill patients in intensive care units (ICUs) often experience complications such as coagulopathy, which can lead to thrombus-related malfunctions in CVVH [3]. Therefore, appropriate selection of hemofilters, modalities, and anticoagulants play a crucial role in the stable performance of CVVH for sessions lasting longer than 24 h [4-6]. Polysulfone (PS) membranes are widely used as hemofilters because of their excellent water permeability and biocompatibility, which are thought to prolong filter lifetimes [7]. PS membranes are composed of hollow fibers covered with polyvinylpyrrolidone (PVP) as a hydrophilic agent. The PVP covering and the shape of the hollow fibers have been shown to affect circuit lifetimes [8]. Therefore, the purpose of the present study was to compare circuit lifetimes when using two types of PS hemofilters in CVVH for critically ill patients with AKI.

\section{Methods}

\section{Patients}

This study was approved by the Institutional Review Board of Sapporo Medical University (no. 302-54). The participants were patients with AKI who underwent CVVH from January to July 2017. Eligible patients were those who had undergone CVVH and met the Kidney Disease Improving Global Outcomes (KDIGO) criteria [9] stage 1 or higher. The patients were divided into two groups as follows: an SHG group that used Hemofeel ${ }^{\circ}$ SHG-1.3 PS membranes (surface area, $1.3 \mathrm{~m}^{2}$; Toray Medical, Tokyo, Japan) and an AEF group that used Excelflo ${ }^{\circ}$ AEF-13 PS membranes (surface area, $1.3 \mathrm{~m}^{2}$; Asahi Kasei Medical, Tokyo, Japan).

\section{Data collection}

Patients' characteristics, including age, gender, underlying diseases, acute physiology and chronic health evaluation (APACHE) II scores, sequential organ failure assessment (SOFA) scores, and the Japanese Association for Acute Medicine-disseminated intravascular coagulation (DIC) scores [10] were recorded and evaluated, and laboratory data, including total protein (TP), hematocrit (Ht), platelet count (PLT), activated partial thromboplastin time (APTT), and activated coagulation time (ACT), were collected from medical charts. Conditions for performing CVVH, including blood flow rate (QB), filtration flow rate (QF), and delivered dose of anticoagulant, were recorded. Serial changes in inlet chamber pressure
(P-inlet), outlet chamber pressure (P-outlet) and filtration chamber pressure (P-filtration) were evaluated. Transmembrane pressure (TMP) was calculated using the following formula:

TMP $=[($ P-outlet $-\mathrm{P}$-inlet $) / 2-\mathrm{P}$-filtration $]$.

The target CVVH duration was set to more than $48 \mathrm{~h}$. Therefore, the CVVH circuit lifetime was defined as the time until a malfunction was identified. A CVVH malfunction was defined as problems in extracorporeal circulation or either a $100-\mathrm{mmHg}$ increase in P-inlet or a $50-\mathrm{mmHg}$ decrease in P-filtration from baseline. Serial TMP change rates from baseline were calculated at 6 , 12 , and $24 \mathrm{~h}$ after the start of CVVH. Baseline TMP was set to $0.5 \mathrm{~h}$ after $\mathrm{CVVH}$ initiation because the initial instability of CVVH stabilizes within $0.5 \mathrm{~h}$. The following formula was used to calculate the TMP change rate:

Rate of change in TMP $(\%)=[($ measured TMP - initial TMP) / initial TMP] $\times 100$.

\section{CVVH materials and apparatus used in this study}

Table 1 shows the specifications of the hemofilters used in this study. The hollow fibers in the SHG membrane had a smaller internal diameter and a thinner film compared with the AEF membrane. The length of the container, that is, the length of the hollow fiber, was also longer in the SHG than in the AEF membrane. The devices used in this study were a blood purification machine (TR-55X; Toray Medical), an extracorporeal circuit (JCH-SMU; Japan Lifeline, Tokyo, Japan), and replacement fluid (SUBPACK-Bi ${ }^{\oplus}$; Nipro, Tokyo, Japan). Nafamostat mesilate was administered as an anticoagulant during $\mathrm{CVVH}$.

\section{Statistical analysis}

Data are expressed as the median (interquartile range [IQR]) unless otherwise stated. A comparison of the two groups was performed using the Mann-Whitney $U$ test. Categorical variables were analyzed using Fisher's exact test. A $p$ value less than 0.05 was considered statistically significant. Serial changes in the TMP change rate were analyzed using the Kruskal-Wallis test. When a statistically significant difference was observed, the Steel-

Table 1 Specification of hemofilter

\begin{tabular}{lll}
\hline & Hemofeel SHG-1.3 & Excelflo AEF-13 \\
\hline Surface area $\left(\mathrm{m}^{2}\right)$ & 1.3 & 1.3 \\
Inner diameter $(\mu \mathrm{m})$ & 200 & 225 \\
Thickness $(\mu \mathrm{m})$ & 40 & 45 \\
length of the hollow fiber $(\mathrm{mm})$ & 195 & 150 \\
Sterilization & Gamma & Gamma \\
& sterilization & sterilization \\
Priming volume $(\mathrm{mL})$ & 85 & 97 \\
Ultrafiltration performance $(\mathrm{mL} / \mathrm{h})$ & 3000 & 2800 \\
\hline
\end{tabular}


Dwass test was performed. The CVVH time within $48 \mathrm{~h}$ in each group was analyzed using the Kaplan-Meier method and compared between groups using the log-rank test.

\section{Results}

The SHG group comprised eight patients and underwent 10 sessions and the AEF group comprised nine patients and underwent 14 sessions. In total, $24 \mathrm{CVVH}$ sessions in the ICU using two types of PS membranes were included.

Table 2 shows the patients' characteristics. No significant differences were observed between the two groups in APACHE II, SOFA, and DIC scores or in KDIGO stage. Furthermore, no significant differences were found between the two groups in laboratory data, including TP, $\mathrm{Ht}$, PLT, APTT, and ACT, or in CVVH conditions including modality, QB, and QF (Table 3). In addition, no significant differences were seen in the delivered dose of anticoagulant between groups.

Figure 1 shows the lifetime of the CVVH circuit analyzed by the Kaplan-Meier curve with the impossibility of extracorporeal circulation or either a $100-\mathrm{mmHg}$ increase in P-inlet or a $50-\mathrm{mmHg}$ decrease in P-filtration from baseline as the endpoint. Although no significant differences in the circuit lifetime of CVVH were seen

Table 2 Demographics of patients prior to CRRT

\begin{tabular}{|c|c|c|c|}
\hline & SHG group & AEF group & $\mathrm{p}$ \\
\hline Number & 8 & 9 & - \\
\hline Session & 10 & 14 & - \\
\hline Age (years) & $56[38-76]$ & $63[41-65]$ & 0.962 \\
\hline Gender (male/female) & $3 / 5$ & $6 / 3$ & 0.347 \\
\hline \multicolumn{4}{|l|}{ Etiology of AKI } \\
\hline Sepsis & 4 & 5 & \\
\hline Severe acute pancreatitis & 1 & 1 & \\
\hline Other & 3 & 3 & 1.000 \\
\hline APACHE I| score & 24 [22-27] & 23 [16-25] & 0.629 \\
\hline SOFA score & 10 [9-12] & $9[7-10]$ & 0.525 \\
\hline DIC score & $5[5-7]$ & $5[5-7]$ & 0.763 \\
\hline KDIGO stage & $1[1-3]$ & $1[1-3]$ & 0.956 \\
\hline \multicolumn{4}{|l|}{ Laboratory data } \\
\hline $\mathrm{TP}(\mathrm{g} / \mathrm{dL})$ & $5.5[5.1-5.5]$ & $5.5[5.2-5.5]$ & 0.730 \\
\hline Hematocrit (\%) & $29.8[22.5-34.2]$ & $30.9[24.3-35.7]$ & 1.000 \\
\hline Platelet $\left(\times 10^{4} / \mu \mathrm{L}\right)$ & $32.5[23.0-48.3]$ & $95.0[40.0-245.0]$ & 0.176 \\
\hline APTT (s) & $45.8[41.0-57.8]$ & $45.5[37.9-65.1]$ & 1.000 \\
\hline$A C T(s)$ & $272[256-284]$ & 241 [208-291] & 0.334 \\
\hline
\end{tabular}

CRRT continuous renal replacement therapy, APACHE acute physiology and chronic health evaluation, SOFA sequential organ failure assessment, DIC disseminated intravascular coagulation, KDIGO Kidney Disease Improving Global Outcomes, TP total protein, APTT activated partial thromboplastin time, $A C T$ activated coagulation time
Table 3 Method of CRRT

\begin{tabular}{llll}
\hline & SHG group & AEF group & $\mathrm{p}$ \\
\hline $\begin{array}{l}\text { Blood flow rate } \\
\text { (mL/min) }\end{array}$ & $150[150-150]$ & $150[150-150]$ & 0.099 \\
$\begin{array}{l}\text { Filtration flow rate } \\
\text { (mL/h) }\end{array}$ & $2000[1120-2080]$ & $2050[2000-2100]$ & 0.219 \\
$\begin{array}{l}\text { Dose of anticoagulant } \\
\text { (mg/h) }\end{array}$ & $30[30-30]$ & $30[30-30]$ & 0.447 \\
$\begin{array}{l}\text { Baseline Pressure } \\
\begin{array}{l}\text { Inlet chamber } \\
\text { (mmHg) }\end{array}\end{array}$ & $130[126-142]$ & $111[105-117]$ & $<0.001$ \\
$\begin{array}{l}\text { Filtration chamber } \\
\text { (mmHg) }\end{array}$ & $78[55-92]$ & $41[35-49]$ & 0.030 \\
$\begin{array}{l}\text { Transmembrane } \\
\text { (mmHg) }\end{array}$ & $36[30-47]$ & $44[40-56]$ & 0.114 \\
\hline
\end{tabular}

CRRT continuous renal replacement therapy

between the two groups, the circuit lifetime in the SHG group tended to be longer than that in the AEF group. The baseline pressures of P-inlet and P-filtration in the SHG group were significantly higher than those in the AEF group. No significant difference in the baseline TMP was found between the two groups.

In the SHG group, no significant differences were observed in the TMP change rate at 6,12 , and $24 \mathrm{~h}$ after the start of CVVH (Fig. 2). However, in the AEF group, the TMP change rate was increased to $35 \%$ (range, 34$39 \%)$ at $12 \mathrm{~h}$ after the start of CVVH $(p=0.007)$ and to $38 \%$ (range, $32-41 \%)$ after $24 \mathrm{~h}(p=0.016)$.

\section{Discussion}

The objective of the present study was to compare $\mathrm{CVVH}$ circuit lifetimes using two types of PS membranes available in Japan. Although no significant differences in the CVVH circuit lifetimes of two types of PS membranes were observed, circuit lifetime tended to be longer in the SHG group. In addition, the TMP change rate over the study period was also more stable in the SHG compared with the AEF group. In spite of using the same material, hemofilters have different properties according to each manufacturer, such as shape and PVP coverage on the surface of the hollow fibers, which were thought to explain the findings of the present study.

In general, one of the determinants which affects circuit lifetimes during CVVH is the hemofilter length/ diameter (L/D) ratio [11]. This may be because of the decreased retention of blood inside the hollow fibers and the reduced shear stress associated with a larger L/ $D$ ratio $[11,12]$.

Compared with hollow fibers in AEF membranes, those in SHG membranes are longer and thinner and have a smaller diameter, and thus a larger $\mathrm{L} / \mathrm{D}$ ratio. These properties of the SHG membranes resulted in higher pressures of $\mathrm{P}$-inlet and P-filtration compared 


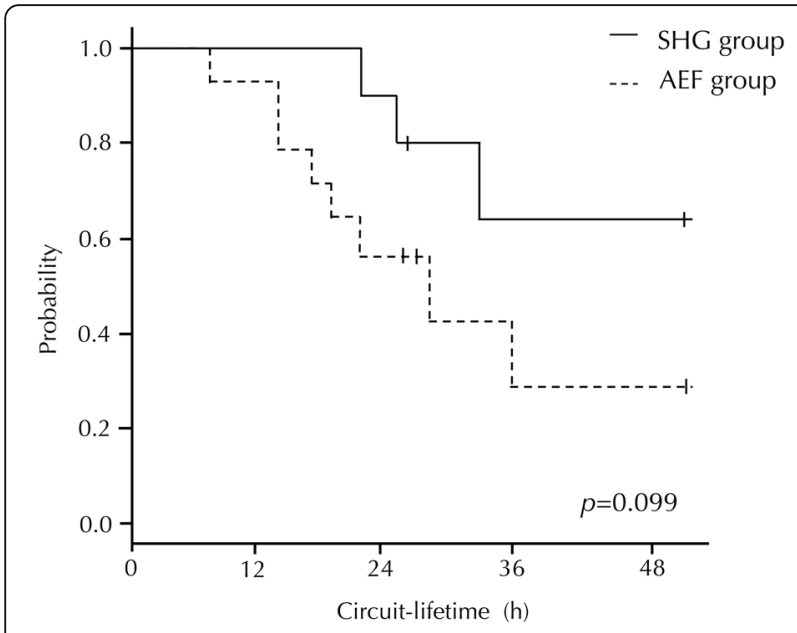

Fig. 1 Kaplan-Meier plots for 48-h circuit lifetimes in continuous renal replacement therapy (SHG group vs. AEF group)

with those of the AEF membranes; however, no differences in TMP were observed between the SHG and AEF membranes. This larger L/D ratio reduces blood retention and shear stress on the membrane surface, meaning that SHG membranes could have longer circuit lifetimes than AEF membranes. The superiority of the CVVH circuit lifetime for SHG in the present study may be due in part to its shape and low shear stress compared with AEF.

The TMP change rate may be influenced by fowling owing to the adhesion of proteins and blood cells to the membrane surface, which also affects the circuit lifetime [13]. Factors affecting membrane fowling from the viewpoint of the equipment include the QF/ QB ratio and the dilution method. On the other hand, from the viewpoint of the biological side, factors related to blood viscosity, such as blood cell count and plasma protein concentration, may be considered. In the present study, no statistically significant differences were found in these factors between the two groups, suggesting that the hemofilter shape and membrane surface characteristics affected the results. PS membranes are hydrophobic, so they must be coated with PVP, a hydrophilizing agent. In addition to its hydrophilic actions, PVP is used to control pore size and distribution [14, 15]. When PVP of an appropriate molecular weight is mixed in an appropriate ratio in a PS membrane, the surface is lubricated and soft, enabling the inhibition of platelet adhesion and fibrinogen adsorption [16]. The SHG membranes were modified so that PVP coverage was thicker and more homogeneous in the hydrophilic layers compared with prior products [8]. This suggests that the reduction of fowling owing to the decreased adhesion of blood cells to the SHG membrane surface contributed to the stable TMP observed.

CVVH could be performed continuously for $24 \mathrm{~h}$ or longer, and satisfactory effects were achieved. In addition, most of the patients who received CVVH were critically ill and often presented with coagulation and fibrinolysis abnormalities resulting from invasive stress. Therefore, to maximize the therapeutic effectiveness of $\mathrm{CVVH}$ in critically ill patients, it is necessary to consider not only QD and QF settings and anticoagulants but also the properties of hemofilters, including the membrane shape and surface treatment. From the viewpoint of extracorporeal circulation biocompatibility, SHG hemofilters may thus be considered suitable for CVVH in critically ill patients with AKI.

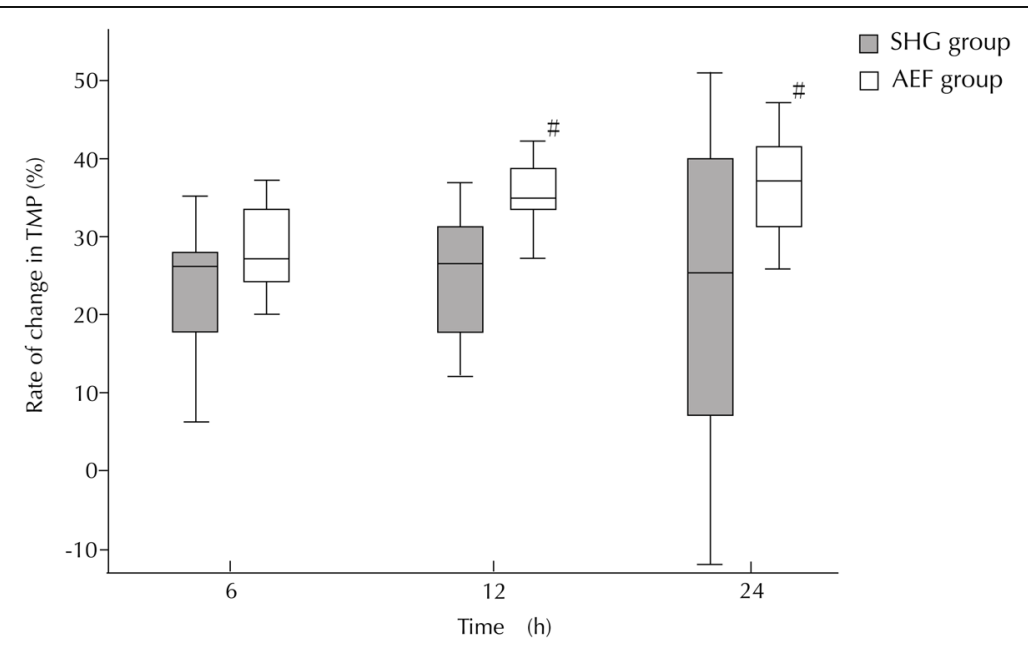

Fig. 2 Rate of change in transmembrane pressure. Box plot: Center lines indicate the medians; box limits indicate the 25th and 75th percentiles; whiskers extend 1.5 times the interquartile range from the 25 th and 75 th percentiles. \#p $<0.05$ compared with $6 \mathrm{~h}$. Time $6 \mathrm{~h}$ is the rate of change in $0-6 \mathrm{~h}$. Time $12 \mathrm{~h}$ is the rate of change in $0-12 \mathrm{~h}$. Time $24 \mathrm{~h}$ is the rate of change in $0-24 \mathrm{~h}$. TMP transmembrane pressure 


\section{Conclusion}

The biocompatibility of PS membrane hemofilters produced by different manufacturers was retrospectively evaluated in relation to CVVH circuit lifetimes. Even though the same PS membranes were used to perform CVVH, differences in the shape of the hollow fibers and treatment of the membrane surfaces affected the circuit lifetime and reduced the stress to the membrane during $\mathrm{CVVH}$ in patients with severe AKI. These results suggest that to maximize the potential of hemofilters when performing CVVH in critically ill patients with AKI, it is necessary to choose a hemofilter based on not only the material but also the shape and treatment of the membrane surface.

\begin{abstract}
Abbreviations
ACT: Activated coagulation time; APACHE II score: Acute physiology and chronic health evaluation II score; APTT: Activated partial thromboplastin time; CWH: Continuous venovenous hemofiltration; DIC score: Disseminated intravascular coagulation score; Ht: Hematocrit; ICU: Intensive care unit; KDIGO criteria: Kidney disease improving global outcomes criteria; PLT: Platelet; QB: Blood flow rate; QD: Dialysate flow rate; QF: Filtration flow rate; SOFA score: Sequential organ failure assessment score;

TMP: Transmembrane pressure; TP: Total protein
\end{abstract}

\section{Acknowledgements}

We thank all the staffs at the Division of Clinical Engineering, Sapporo Medical University Hospital, who provided help and support for this research.

\section{Funding}

No funding was received for this study.

\section{Availability of data and materials}

Data are available on request.

\section{Authors' contributions}

YN designed the study and wrote the initial draft of the manuscript. SC contributed to the analysis and interpretation of the data and assisted in the preparation of the manuscript. All other authors contributed to the data collection and interpretation and critically reviewed the manuscript. All authors approve the final version of the manuscript, agree to be accountable for all aspects of the work, and ensure that all questions related to the accuracy or integrity of any part of the work were appropriately investigated and resolved.

\section{Ethics approval and consent to participate}

The study protocol was approved by the ethics committee of the Sapporo Medical University, Hokkaido, Japan. In addition, the clinical trial study protocol was also checked and approved by the institutional review board of Sapporo Medical University, Hokkaido, Japan.

\section{Consent for publication}

Since this was a retrospective study, patient consent was not considered necessary; however, all relevant research information was disclosed.

\section{Competing interests}

The authors declare that they have no competing interests.

\section{Publisher's Note}

Springer Nature remains neutral with regard to jurisdictional claims in published maps and institutional affiliations.

\section{Author details}

'Division of Clinical Engineering, Sapporo Medical University Hospital, South-1, West-16, Chuo-ku, Sapporo, Hokkaido 060-8543, Japan. ${ }^{2}$ Department of Intensive Care Medicine, Sapporo Medical University School of Medicine, Sapporo, Japan.
Received: 2 August 2018 Accepted: 5 December 2018

Published online: 06 January 2019

\section{References}

1. Uchino S, Fealy N, Baldwin I, et al. Pre-dilution vs. post-dilution during continuous veno-venous hemofiltration: impact on filter life and azotemic control. Nephron Clin Pract. 2003;94:94-8.

2. Baldwin I. Factors affecting circuit patency and filter 'life'. Contrib Nephrol. 2007;156:178-84.

3. Nurmohamed SA, Jallah BP, Vervloet MG, et al. Predilution versus postdilution continuous venovenous hemofiltration: no effect on filter life and azotemic control in critically ill patients on heparin. ASAIO J. 2011;57:48-52.

4. Pichaiwong W, Leelahavanichkul A, Eiam-ong S. Efficacy of cellulose triacetate dialyzer and polysulfone synthetic hemofilter for continuous venovenous hemofiltration in acute renal failure. J Med Assoc Thail. 2006;89:565-72.

5. Ricci Z, Ronco C, Bachetoni A, et al. Solute removal during continuous renal replacement therapy in critically ill patients: convection versus diffusion. Crit Care. 2006;10:R67.

6. Fealy $\mathrm{N}$, Aitken $\mathrm{L}$, du Toit $\mathrm{E}$, et al. Faster blood flow rate does not improve circuit life in continuous renal replacement therapy: a randomized controlled trial. Crit Care Med. 2017;45:1018-25.

7. Kawabata K, Nakai S, Miwa M, et al. Platelet GPIllb/lla is activated and platelet-leukocyte coaggregates formed in vivo during hemodialysis. Nephron. 2002:90:391-400.

8. Kokubo K, Kurihara Y, Tsukao H, et al. Effects of increased surface coverage of polyvinylpyrrolidone over a polysulfone hemofilter membrane on permeability and cell adhesion during continuous hemofiltration. J Artif Organs. 2015;18:257-63.

9. Khwaja A. KDIGO clinical practice guidelines for acute kidney injury. Nephron Clin Pract. 2012;120:c179-84.

10. Iba T, Di Nisio M, Thachil J, et al. Revision of the Japanese Association for Acute Medicine (JAAM) disseminated intravascular coagulation (DIC) diagnostic criteria using antithrombin activity. Crit Care. 2016;20:287.

11. Düngen HD, von Heymann C, Ronco C, et al. Renal replacement therapy: physical properties of hollow fibers influence efficiency. Int J Artif Organs. 2001;24:357-66.

12. Hathcock JJ. Flow effects on coagulation and thrombosis. Arterioscler Thromb Vasc Biol. 2006;26:1729-37.

13. Claure-Del Granado R, Macedo E, Chertow GM, et al. Effluent volume in continuous renal replacement therapy overestimates the delivered dose of dialysis. Effluent volume in continuous renal replacement therapy overestimates the delivered dose of dialysis. Clin J Am Soc Nephrol. 2011;6:467-75.

14. Bowry SK, Ronco C. Surface topography and surface elemental composition analysis of helixone, a new high-flux polysulfone dialysis membrane. Int J Artif Organs. 2001;24:757-64.

15. Ochoa N, Prádanos P, Palacio L, et al. Pore size distributions based on AFM imaging and retention of multidisperse polymer solutes: characterisation of polyethersulfone UF membranes with dopes containing different PVP. J Membr Sci. 2001;187:227-37.

16. Hayama M, Yamamoto K, Kohori F, et al. Nanoscopic behavior of polyvinylpyrrolidone particles on polysulfone/polyvinylpyrrolidone film. Biomaterials. 2004;25:1019-28.

Ready to submit your research? Choose BMC and benefit from:

- fast, convenient online submission

- thorough peer review by experienced researchers in your field

- rapid publication on acceptance

- support for research data, including large and complex data types

- gold Open Access which fosters wider collaboration and increased citations

- maximum visibility for your research: over 100M website views per year

At BMC, research is always in progress.

Learn more biomedcentral.com/submissions 